\title{
ENSINAR A “CIDADE" NO ENSINO BÁSICO
}

\author{
Maria Helena Fidalgo Esteves ${ }^{1}$
}

\begin{abstract}
Resumo - Este artigo procura analisar o estudo da cidade nos actuais programas de Geografia e nalguns manuais escolares em vigor. Com a reorganização curricular da Geografia verificamos que, agora, a dimensão mais valorizada, é o desenvolvimento de competências essenciais e menos a memorização de conteúdos. Os novos manuais escolares editados vão responder ao desafio de fazer uma Geografia capaz de contribuir para a formação de cidadãos geograficamente competentes. $O$ estudo da cidade continua a fazer parte importante do novo currículo da Geografia, mas verificam-se poucas alterações em relação aos conteúdos que eram abordados antes da reorganização, pelo menos naquilo que se refere à forma como os manuais escolares abordam este tema.
\end{abstract}

Palavras-chave: Cidade, geografia escolar, reorganização curricular, manuais escolares.

Abstract - TEACHING ABOUT THE CITY IN COMPULSORY SCHOOL. This paper aims at analysing the study of the city in today's Geography programmes and some textbooks currently in use. The recent curricular reform in Geography has bought a new approach to the subject: the most important issue is now the development of essential skills, contrary to former programmes of study more centred on the memorisation of scientific content. Geography textbooks have also been reformulated in order to adequately respond to this challenge of educating geographically skilled citizens. The study of the city remains an important part of this new Geography curriculum, but few changes have been made considering the scientific content in the previous curricula, at least in the way textbooks approach this subject.

Key words: Urban geography, school geography, curricular reform, textbooks.

Résumé - ENSEIGNER LA VILLE DANS L'ENSEIGNEMENT DE BASE. On tente l'analyse de l'étude de la ville, telle qu'elle apparaît dans les actuels programmes de Géographie et dans quelques manuels. Les programmes actuels valorisent surtout l'acquisition de compétences essentielles par les élèves, au détriment de la mémorisation des faits. Les

${ }^{1}$ Assistente do Departamento de Geografia da Faculdade de Letras da Universidade de Lisboa e investigadora do Centro de Estudos Geográficos. E-mail: mesteves@fl.ul.pt 
manuels scolaires récemment publiés tentent de répondre au défit de proposer une Géographie destinée surtout à former des citoyens géographiquement compétents. L'étude de la ville y conserve une part importante, sans qu'on note de changements importants concernant les contenus abordés avant la réorganisation, ni dans la façon de les aborder. scolaires.

Mots-clés: Ville, geógraphie scolaire, réorganisation des programmes, manuels

\section{INTRODUÇÃO}

O presente artigo tem como objectivo analisar a forma como o estudo da "cidade" é realizado no âmbito da disciplina de Geografia no Ensino Básico. Ensinar a "cidade" é uma actividade que coloca muitos desafios aos professores, se pensarmos que muitas vezes a cidade apresentada na sala de aula, no currículo nacional e nos manuais escolares, é bem diferente da cidade percepcionada por cada estudante.

O currículo das disciplinas leccionadas no Ensino Básico foi recentemente objecto de uma reorganização cujo objectivo principal consistiu em adaptar a realidade escolar aos novos desafios que os jovens irão enfrentar enquanto cidadãos de um mundo complexo e global (Ministério da Educação, 2001). A disciplina de Geografia foi igualmente alvo desta reorganização procurando dar resposta ao desafio de ser capaz de ter um «outro olhar sobre o mundo» (Cachinho, 2002). Considerando que a Geografia esco$1 \mathrm{r}^{2}$ é determinada por um grande número de factores que estão em permanente mudança, a definição dos currículos debate-se cada vez mais com a necessidade de adaptação às mudanças sociais que o País e o mundo enfrentam.

A reorganização curricular das disciplinas do Ensino Básico teve igualmente a finalidade de contribuir para uma concepção de currículo mais aberta e abrangente associada à valorização de práticas de gestão curricular mais flexíveis e adequadas a cada contexto (Ministério da Educação, 2001). Esta orientação esteve igualmente presente na reorganização curricular da disciplina de Geografia.

No quadro desta procurou dar-se aos professores mais liberdade no que se refere ao trabalho a desenvolver com os alunos na sala de aula. Neste sentido a reorganização curricular pretendeu diminuir a carga de conteúdos das disciplinas, passando a dar mais relevância ao desenvolvimento de competências essenciais (as competências que permitirão aos estudantes a leitura do mundo próximo e distante, e a capacidade de actuar perante as mais diversas situações).

A sociedade global é urbana (Souto Gonzalez et al., 1994). À medida que o ritmo da globalização aumenta e o mundo pós-moderno se torna cada vez menor, a compreensão das complexidades do mundo deve ser incentivada e melhorada. Sabemos que as questões que mais preocupam os jovens abrangem temas tão diversos como a degradação ambiental, as mudanças climáticas, os conflitos regionais, a urbanização do mundo e suas consequências, a pobreza, entre outros (Hicks, 1994).

Estudos mais recentes sobre estudantes portugueses demonstraram que estas questões também estão presentes na sua visão do mundo (Esteves, 2002). Todos os temas

${ }^{2}$ Conceito desenvolvido procurando dar resposta aos problemas que se colocam à Geografia no contexto da educação (Cachinho, 2002). 
referidos são do âmbito da Geografia. Entre eles a questão urbana aparece como um tema que preocupa os jovens nas mais diversas dimensões. Torna-se assim importante analisar como esta questão é presentemente tratada no currículo nacional da Geografia e nos materiais de apoio a professores e alunos.

\section{A “CIDADE” NO CURRÍCULO NACIONAL}

Apesar de ser um assunto transversal ${ }^{3}$ que aparece em todos os temas organizadores do currículo do $3 .^{\circ}$ ciclo, é efectivamente no Tema 3 - População e Povoamento, que as questões relacionadas com a urbanização ${ }^{4}$ vão ser abordadas de forma mais concreta. Considerando que na maioria das escolas portuguesas, os professores de Geografia seguem as orientações curriculares em termos de organização temáticas dos anos lectivos, este tema é abordado junto de estudantes do 8.\% $/{ }^{\circ}$ ano. Estamos a falar de uma população escolar cuja idade média ronda os 13/14 anos $^{5}$, que completará brevemente a escolaridade obrigatória 6 .

$\mathrm{O}$ documento de orientações curriculares da Geografia, que corresponde à reorganização curricular actualmente em vigor nas escolas portuguesas, coloca em segundo plano uma visão da Geografia centrada em conteúdos (apesar de não os excluir) e passa a centrar-se num conjunto de competências geográficas essenciais que permitirão ao estudante completar «a educação básica com o conhecimento sistemático do seu próprio país, de outros e do mundo» (Ministério da Educação, 2002).

Introduz igualmente a noção de "cidadão geograficamente competente"7 e pretende que a Geografia escolar não seja apenas uma disciplina de memorização e localização de factos geográficos sem relação aparente entre si. A análise do real é o ponto de partida para que o estudante de Geografia possa compreender fenómenos mais distantes e mais complexos, no sentido de desenvolver capacidade de análise crítica dos mesmos, tomar consciência do dinamismo das relações entre os diversos espaços e assim chegar a um sentimento de pertença global.

A cidade no currículo nacional é abordada em três eixos fundamentais, embora não se exclua a possibilidade de o professor procurar outros temas, de acordo com o interesse dos alunos ou com o contexto escolar (fig. 1).

O currículo da Geografia considera extremamente importante o levantamento de questões sobre os temas em estudo. Se os estudantes aprenderem a questionar e problematizar os temas abordados pela Geografia e, a partir daqui, procurarem descrever e explicar as actividades que observam, certamente desenvolverão competências geográficas muito úteis na leitura do espaço próximo e distante. O documento de Orientações

${ }^{3}$ Referências gerais e constantes a elementos humanos da paisagem.

${ }^{4}$ Conceito relativo ao aumento do espaço urbano, quer em extensão, quer em população.

${ }^{5}$ www.giase.min-edu.pt (Sistema Educativo Português - Situação e Tendências 1900-2000, Lisboa 2004).

${ }^{6}$ Alargada recentemente para os 18 anos, mas correspondendo ao $3 .^{\circ}$ ano do $3 .^{\circ}$ ciclo do Ensino Básico.

${ }^{7}$ Aquele que possui o domínio das destrezas espaciais e que o demonstra ao ser capaz de visualizar espacialmente os factos, relacionando-os entre si, de descrever correctamente o meio em que vive ou trabalha, de elaborar um mapa mental desse meio, de utilizar mapas de escalas diversas, de compreender padrões espaciais e compará-los uns com os outros, de se orientar à superfície terrestre (Orientações Curriculares, 2002). 


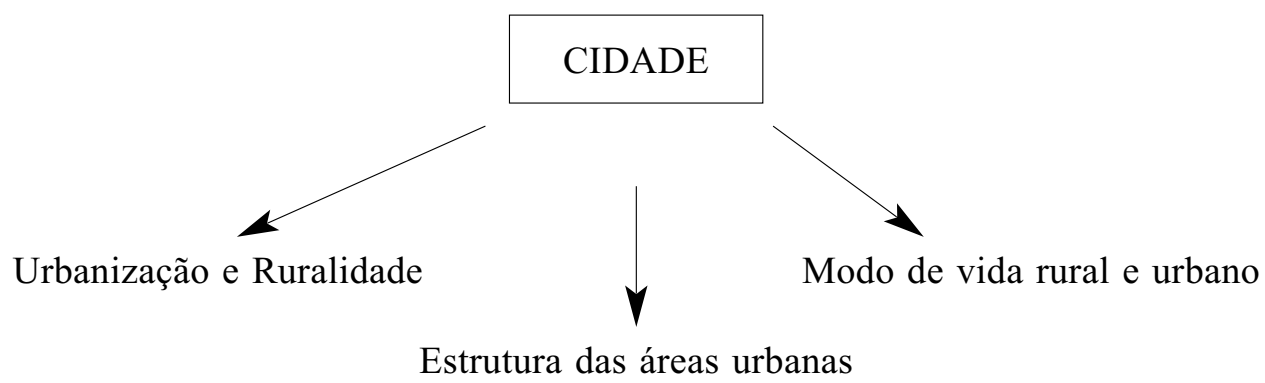

Fig. 1 - Áreas de Fixação Humana: estudo das cidades.

Orientações Curriculares - Geografia, 2002

Fig. 1 - Areas of human settlement: a study of cities. Curricular guidelines - Geography, 2002.

Curriculares sugere assim o levantamento de algumas questões geográficas ${ }^{8}$, a funcionar como pontos de partida para o estudo das cidades:

- Onde se localizam as principais aglomerações urbanas?

- Como se organizam as áreas urbanas?

- Que mudanças ocorrem no uso e ocupação do espaço urbano?

- Como se distingue o modo de vida da população urbana da rural?

- Quais os impactes ambientais e sociais do crescimento e da transformação das áreas urbanas?

São também apresentadas algumas áreas mais específicas relacionadas com os três grandes eixos fundamentais acima referidos:

- Identificar aglomerações urbanas com crescimento populacional contrastado;

- Comparar os modos de vida da população urbana e rural;

- Analisar plantas de cidade e/ou plantas funcionais construídas para relacionar as diferentes formas de uso e de ocupação do solo;

- Analisar mudanças funcionais que ocorrem no espaço urbano;

- Estudar problemas concretos das áreas urbanas em países desenvolvidos e em países em desenvolvimento;

De igual forma o documento sugere alguns exemplos de experiências educativas a desenvolver em torno dos três temas globais apresentados, tal como se apresenta no quadro I.

Convém referir que o mesmo documento considera que a gestão do currículo deverá centrar-se nos aspectos interpretativos das diversas experiências educativas e não apenas nos aspectos descritivos dos conteúdos programáticos. Mais ainda, as experiências educativas são apenas sugestões, exemplos de como as competências essenciais podem ser desenvolvidas, sendo perfeitamente admissível a selecção de outras consideradas mais pertinentes.

Parece claro que o aluno deve desenvolver competências ligadas à observação, recolha de informação, registo da mesma, levantamento de hipóteses e apresentação de resultados. O método investigativo ${ }^{9}$ torna-se assim o paradigma para a educação geo-

${ }^{8}$ Questões que resultam da percepção dos estudantes resultado das suas observações e concepções (Orientações Curriculares, 2002). 
gráfica. Investigar a "cidade" é assim procurar respostas para as questões que os alunos colocam sobre aquilo que observam; cabe ao professor organizar as situações de aprendizagem, para ajudar os alunos a encontrar as respostas.

Quadro I - Sugestões de experiências educativas a realizar no estudo das cidades (exemplos) Orientações Curriculares - Geografia, 2002.

Table I - Suggestions for learning activities when studying cities (examples. Curricular guidelines - Geography, 2002.

\begin{tabular}{ll}
\hline \multicolumn{1}{c}{ Temas } & \multicolumn{1}{c}{ Sugestão de experiências educativas } \\
\hline $\begin{array}{l}\text { Urbanização } \\
\text { e ruralidade }\end{array}$ & - Recolher informações sobre os espaços urbanos e rurais de Portugal e de outros países \\
& - Construir quadros para apresentação da informação (gráficos, mapas, etc.) \\
$\begin{array}{l}\text { Estrutura } \\
\text { das Áreas }\end{array}$ & $\begin{array}{l}\text { - Realizar trabalho de campo na área envolvente } \\
\text { Urbanas }\end{array}$ \\
$\begin{array}{l}\text { - Realizar plantas de cidade } \\
\text { urbano }\end{array}$ \\
$\begin{array}{ll}\text { Modos de vidados que evidenciem as mudanças funcionais que ocorrem no espaço } \\
\text { urbano e rural }\end{array}$ & $\begin{array}{l}\text { Recolher informações utilizando materiais diversificados como livros, } \\
\text { fotos, vídeos, etc., para compreender as diferenças entre os modos de vida }\end{array}$ \\
\hline
\end{tabular}

Comparando esta reorganização curricular com o Programa de Geografia - 3. ${ }^{\circ}$ ciclo (1994) que orientou o trabalho de professores e alunos durante cerca de uma década e, no caso concreto, do ponto relativo ao estudo das cidades (As cidades: centros de organização do território), as diferenças não são marcantes. Efectivamente, os conteúdos encontram-se aglomerados em torno de três temas gerais: áreas rurais e áreas urbano - industriais, características das áreas urbanas e diversidade das funções urbanas. O ensino da "cidade" aparece assim numa continuidade do que parece ser um conjunto de temas e conceitos pertinentes para a Geografia escolar.

\section{A “CIDADE” NOS MANUAIS ESCOLARES}

Considerando a reorganização curricular de que foi alvo a Geografia no Ensino Básico, as editoras de manuais escolares sentiram necessidade de repensar os manuais de apoio à disciplina. E, tal como aconteceu aos conteúdos programáticos no Currículo Nacional, os manuais "emagreceram" em termos de conteúdos e procurou-se investir em sugestões de actividades, no sentido de tornar a disciplina mais ligada a metodologias de carácter activo.

Procedemos à análise dos manuais escolares segundo as orientações definidas por Souto Gonzalez (1998), no que diz respeito à estrutura apresentada relativamente às temáticas abordadas. Procurou-se ver de que forma os manuais também se reorganizaram para responder às novas solicitações do currículo nacional, mais concretamente no caso do ensino relacionado com as questões urbanas.

Para compreender melhor as alterações verificadas no conteúdo dos manuais escolares, foram seleccionados dois manuais relativos ao Ponto 3 - População e Povoamento,

${ }^{9}$ É central na educação geográfica já que permite desenvolver competências importantes e assim contribuir para uma cidadania participativa e consciente (Orientações Curriculares, 2002). 
no sentido de analisar de que forma as questões urbanas são apresentadas ${ }^{10}$. Sabemos que, sem uma formação adequada é difícil modificar as práticas dos professores, e que, apesar de alguma formação e informação que vai decorrendo a nível escolar, cabe aos professores a tarefa de implementar na sala de aula as grandes alterações presentes na reorganização curricular. O manual escolar continua a ter um papel de apoio importante para professores e alunos, quando outros canais de transmissão de informação falham.

A transição de uma metodologia de ensino centrada nos conteúdos programáti$\cos$, relativamente àquilo que os alunos devem aprender, para uma forma de leccionar centrada no aluno e no desenvolvimento de competências essenciais, é certamente uma tarefa difícil quando muitas práticas estão interiorizadas em professores, alunos, escolas e pais, e a resistência à mudança é uma realidade. Os manuais escolares, analisados na forma como ensinam a cidade, representam também essa transição para um ensino capaz de formar cidadãos geograficamente competentes.

Como já se referiu, o "emagrecimento" em termos de conteúdos é um facto. Muda igualmente a linguagem dos manuais, isto é, deixam de ter um carácter de apoio ao professor, para se dirigirem directamente aos alunos. O manual fala para o aluno, numa clara tentativa de o centrar no processo de ensino - aprendizagem. Um outro aspecto a salientar é a necessidade de os manuais ainda fazerem uma sistematização dos conhecimentos a reter, apesar de se evitar uma linguagem muito ligada à definição de objectivos de ensino ${ }^{11}$.

Voltando à questão dos conceitos básicos relativos ao estudo da cidade, não existem muitas diferenças em relação à forma como as temáticas urbanas são apresentadas (no quadro II elas são apresentadas tal como vão surgindo em cada manual).

Quadro II - Conceitos abordados no ensino da Geografia Urbana.

Table II - Concepts covered when teaching Urban Geography.

\begin{tabular}{ll}
\hline \multicolumn{1}{c}{ Manual 1 } & \multicolumn{1}{c}{ Manual 2 } \\
\hline Área urbana/rural & Espaço rural/urbano \\
Taxa de Urbanização & Modo de vida rural/urbano \\
Maiores cidades a nível mundial & Taxa de urbanização \\
Características dos centros urbanos & Urbanização \\
Êxodo rural e êxodo urbano & Características do espaço urbano \\
Factores atractivos e repulsivos & Funções da cidade \\
$\begin{array}{l}\text { Crescimento urbano - problemas, suburbanização, } \\
\text { renovação, requalificação, pressão sobre }\end{array}$ & Organização do espaço urbano (Burgess) \\
$\quad \begin{array}{l}\text { as áreas rurais } \\
\quad \text { Modelo de Burgess) }\end{array}$ & \\
$\begin{array}{l}\text { Funções dos centros urbanos } \\
\text { (hierarquia, bens e funções) }\end{array}$ & Problemas sociais no espaço urbano \\
$\begin{array}{l}\text { A cidade nos Países Desenvolvidos e nos Países } \\
\text { em Vias de Desenvolvimento }\end{array}$ & Problemas ambientais no espaço urbano \\
\hline
\end{tabular}

${ }^{10}$ Procurou-se manter o anonimato dos manuais pelo que serão designados de Manual $1 \mathrm{e}$ Manual 2, ambos editados em 2002.

${ }^{11}$ Tal como se verificava no Programa de Geografia - Ensino Básico - $3^{\text {o }}$ ciclo, 1994. 
Tal como já se tinha verificado com os temas da Geografia Urbana presentes na reorganização curricular, parece que os manuais escolares continuam a ter um organização centrada num conjunto de conceitos de carácter científico que são apresentados a professores e alunos como aquilo que deverão saber para aprender a cidade. Relativamente às actividades de aprendizagem sugeridas estas seguem grosso modo as orientações curriculares (quadro III).

Quadro III - Actividades de aprendizagem sugeridas pelos manuais.

Table III - Learning activities suggested by the textbooks.

\begin{tabular}{ll}
\hline \multicolumn{1}{c}{ Manual 1 } & \multicolumn{1}{c}{ Manual 2 } \\
\hline $\begin{array}{l}\text { Análise de imagens reais e esquematizadas } \\
\begin{array}{l}\text { Estudos de caso (Cairo, Lisboa, problemas } \\
\text { dos sem-abrigo) }\end{array}\end{array}$ & Análise descritiva de imagens de cidades \\
$\begin{array}{l}\text { Jogos didácticos - Planeamento de um centro } \\
\text { urbano, jogo sobre os sem-abrigo }\end{array}$ & Trabalho de campo \\
$\begin{array}{l}\text { Levantamento funcional } \\
\text { Questionários à população urbana } \\
\text { Trabalho de campo - área envolvente da escola }\end{array}$ & Questionários à população \\
\hline
\end{tabular}

A preocupação no desenvolvimento de actividades de investigação é um facto. De uma maneira geral o quadro III mostra que os autores se preocuparam em dar uma resposta concreta às orientações curriculares, no que se refere à escala de análise dos temas, assim como às experiências educativas a implementar na sala de aula. Verificamos assim que na abordagem das questões urbanas a dimensão local está presente, através do estudo da área envolvente da escola, levantamentos funcionais e elaboração de questionários à população. Esta dimensão de abordagem do real é particularmente privilegiada nas orientações curriculares da Geografia na medida em que valoriza o desenvolvimento da capacidade de observação e análise do espaço envolvente - o primeiro passo para compreender o meio (Ministério da Educação, 2002).

Aparecem igualmente actividades ligadas a outras escalas de análise, pretendendo que os estudantes sejam capazes de transportar para novas dimensões de análise da realidade urbana, as questões inicialmente tratadas à escala local. Os jogos didácticos, a análise descritiva de imagens e os estudos de caso terão certamente um papel importante no alargamento da compreensão do mundo, e das múltiplas relações entre os fenómenos, nomeadamente os relacionados com o estudo da cidade.

\section{REFLEXÕES FINAIS}

O ensino da "cidade" no Ensino Básico, tal com se procurou demonstrar pela análise dos documentos relativos à reorganização curricular da Geografia e de dois manuais escolares, parece não ter sido alvo de grandes mudanças. Com efeito, parece que não são apenas as práticas de professores e alunos que são resistentes à mudança, principalmente quando esta não se formaliza em programas de formação contínua.

Se, por um lado, a análise dos manuais escolares traduz uma maior preocupação com a promoção de novas situações de aprendizagem, tal com apresentamos no quadro III, é também verdade que reflectem a forma como as práticas escolares continuam 
a ter a marca das informações que veiculam (Claudino, 2002). No caso particular das questões urbanas, tal situação é um facto.

A forma como o estudo das cidades é apresentada nos manuais escolares parece não ter absorvido as grandes mudanças que se verificaram na própria evolução do espaço urbano. Quase se poderia dizer que os manuais continuam a ensinar a cidade que os seus autores, também professores de Geografia, aprenderam nas Universidades enquanto estudantes. É interessante verificar que o Modelo de Estrutura Urbana desenvolvido por Burgess em 1925, continua a dominar a imagem de cidade que os manuais apresentam, como se esta ainda fosse a imagem de cidade que professores e estudantes têm (Machon, 1996). A cidade que apresentam é assim um espaço funcionalmente organizado em torno de um centro polarizador, enquanto a cidade em que os alunos vivem tem cada vez menos a ver com esta imagem do espaço urbano.

A necessidade de reorganizar os conteúdos disciplinares de várias disciplinas e também da Geografia tem sido justificada pelo facto de a Geografia escolar não poder ser uma versão simplificada do currículo universitário. O que se verifica é que a Geografia escolar continua agarrada a paradigmas que a Geografia universitária já reelaborou.

A cidade pós-moderna e fragmentada, que se opõe à cidade moderna que apresentava uma segregação funcional e social (Barata Salgueiro, 1998), não existe ainda nos manuais escolares da Geografia. Quase poderíamos pensar que não existiu efectivamente uma reorganização curricular da Geografia, se nos baseássemos apenas na apreciação daquilo que os manuais nos apresentam como os conteúdos mais importantes para o estudo das cidades.

$\mathrm{Na}$ medida em que vivemos num mundo cada vez mais urbanizado, torna-se particularmente importante estudar como se organizam as cidades, as transformações que têm sofrido e de que forma condicionam os modos de vida. Num país onde as taxas de urbanização têm vindo a aumentar, o espaço reservado ao estudo das cidades deveria ser reformulado e actualizado no que se refere à Geografia escolar.

Apesar de ser claro que a ênfase está agora no desenvolvimento de competências essenciais e não na memorização de conteúdos, parece que de alguma forma a formação contínua, mais do que nunca, deve continuar a funcionar como área de actualização dos professores de Geografia. Só assim se poderão proporcionar aos estudantes experiências educativas capazes de ensinar a ler a cidade em que existimos.

Barata Salgueiro T (1998) Cidade pósmoderna. Espaço fragmentado. Inforgeo, 12/13: 225-236.

Burgess E (1925) The growth of the city. In Park R, et al. (ed) The City. Oxford University, Chicago: 47-62.

Cachinho H (2002) Geografia escolar: orientação teórica e praxis didáctica. Inforgeo, 2000: 69-90 .

Claudino S (2005) Educação geográfica, divisões administrativas e cidadania local: o desafio incontornável. Apogeo: $34-42$.

Esteves H (2002) Preocupações ambientais dos estudantes do ensino básico. Contributo para a didáctica da Geografia. Inforgeo, 2000: 137-151.

Hicks D (1994) Educating for the future: a practical classroom guide. WWF, Godalming. 
Machon (1996) Change in school geography. In Bailey P, Fox P (eds) Geography teachers handbook. The Geographical Association, Sheffield: 39-46.

Ministério da Educação (1994) Programa de geografia - plano de organização do ensino - aprendizagem - 3. ${ }^{\circ}$ ciclo. Vol. II. DGEBS, Lisboa.

Ministério da Educação (2001) Currículo nacional do Ensino Básico. Competências essenciais. Departamento da Educação Básica, Lisboa.

Ministério da Educação (2002) Geografia: orientação curricular - 3. ${ }^{\circ}$ Ciclo. Departamento de Educação Básica, Lisboa.

Souto Gonzalez X et al. (1994) El estudio geografico de los problemas urbanos: orientación teórica e praxis didáctica. Nau Libres, Valencia.

Souto Gonzalez X (1998) Didáctica de la Geografia. Ediciones del Serbal, Barcelona. 